\title{
Technological aspects of obtaining melanin and powder from buckwheat hull and their use in food technology
}

\author{
Svetlana Korpacheva $^{1, *}$, Kristina Serasutdinova ${ }^{1}$, Igor Lomovsky ${ }^{2}$, and Olga Chugunova ${ }^{3}$ \\ ${ }^{1}$ Novosibirsk State Technical University, Prospekt K. Marksa, 20, 630073 Novosibirsk, Russia \\ ${ }^{2}$ Institute of Solid State Chemistry and Mechanochemistry of SB RAS, Kutateladze Str., 18, 630128 \\ Novosibirsk, Russia \\ ${ }^{3}$ Ural State University of Economics, 8 Marta Str., 62, 620144 Yekaterinburg, Russia
}

\begin{abstract}
In the paper, technology of melanin and powder from buckwheat (Fagopyrum esculentum) hull obtaining is studied. Buckwheat hull is a by-product of buckwheat grain production and has high antioxidant activity. It is a cheap source for raw material with high content of cellulose and brown melanin pigment. In Russia, buckwheat grain is strategical crop used in child and dietary nutrition. Buckwheat hulls, which production volume is about $22 \%$ of the total volume of processed grain, are practically not used. At the same time, buckwheat hull can be regarded as a valuable raw material for obtaining of several biologically active substances and technological food ingredients due to its unique chemical composition. The possibility and prospects of using products of buckwheat hulls processing in the formulation of dessert with functional properties, is described. It was found that the implementation of buckwheat processing by-products into the desserts increases their antioxidant activity, and addition of fine powder increases dietary fiber content in them.
\end{abstract}

\section{Introduction}

In food industry, by-products are not practically used for further processing. However, their chemical composition allows them to be used as sources of valuable food ingredients in the production of enriched and functional foods. The use of secondary resources in food industry for creation of such food products is one of the main tasks in "The Development Strategy of Food and Processing Industry in Russian Federation for the period up to 2030" and meets the UN Sustainable Development Goals - to ensure sustainable consumption and production patterns. In the paper, the possibility and prospects of using buckwheat hull processed products in the creation of new food products is described.

It is known that Russia is second leader after China in world production of buckwheat grain. Therefore, the disposal of such waste as buckwheat hull is truly relevant for the country. In buckwheat grain production, about $200 \mathrm{~kg}$ of hulls per 1 ton of grain are formed. The volume of buckwheat hulls is about $20 \ldots .22 \%$ of the processed grain total

\footnotetext{
*Corresponding author: korpacheva@corp.nstu.ru
} 
volume. Their quantity is about 63 thousand tons, but only a small part of the hulls is used later.

Buckwheat hulls are mainly used as a filler for pillows and blankets, as fuel, as a material for packaging fruits and fragile goods, and as a feed raw material for animals. However, micro- and macroelements contained in buckwheat hull allows it to be used as a source of biologically active substances.

According to literature data, buckwheat hulls contain about $80 \%$ of cellulose. Therefore, in its content they surpass most of cereal products. Buckwheat hulls also contain lipids $(4 \ldots 5 \%)$, polysaccharides $(70 \%)$, sugars $(0,2 \ldots 0,3 \%)$, ashes $(9 \ldots 10 \%)$, rutin $(0.17 \%)$, vitamin $\mathrm{E}(0.023 \%)$, nicotinic acid $(0.056 \%)$, tannins $(7.5 \%)$, flavonoids and minerals $(\mathrm{K}$, $\mathrm{Na}, \mathrm{Cu}, \mathrm{Ag}, \mathrm{Ca}, \mathrm{Mg}, \mathrm{Zn}, \mathrm{Al}, \mathrm{Fe}, \mathrm{Cr}, \mathrm{P})$ [1-7].

In the buckwheat hull, the leading position among pigments is occupied by melanins, which are localized in the outer layers of buckwheat hull cell walls [8]. According to previously carried out studies, it is known that melanin is involved in cellular metabolism and thus it is considered as universal cell protector against mutagenic and carcinogenic factors [9-12].

As a summary of the review, it can be concluded that by-products of buckwheat processing are valuable raw materials, which can be used in food industry for creating food products with increased nutritional value and antioxidant activity.

\section{Methods and types of the Earth's remote sensing}

Fine powder from buckwheat hulls was obtained in the Laboratory of Solid State of Institute of Solid State Chemistry and Mechanochemistry of Siberian Branch of Russian Academy of Sciences (Novosibirsk). Mechanochemical treatment of the powder was carried out by mechanochemical activation in flow-centrifugal mill activator PM-10. The rotor speed was $1050 \mathrm{rpm}$. Sodium carbonate was used as an additional solid reagent. The average particle size of obtained mechanocomposite was $120 \mu \mathrm{m}$.

Microbiological indices of fine powder are within norms of Technical Regulations of the Customs Union 021/2011 "On food safety". The powder was evaluated for its chemical (Fig. 1) and mineral (Fig. 2) compositions using standard methods.

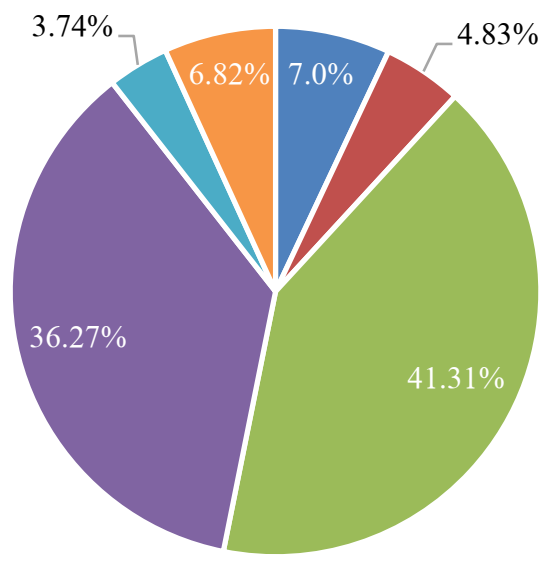

- Humidity, \%

- Proteins, $\%$

- Sugars, \%

- Dietary fiber, $\%$

- Pectin , \%

- Crude ash, \%

Fig. 1. Chemical composition of buckwheat hull fine powder. 


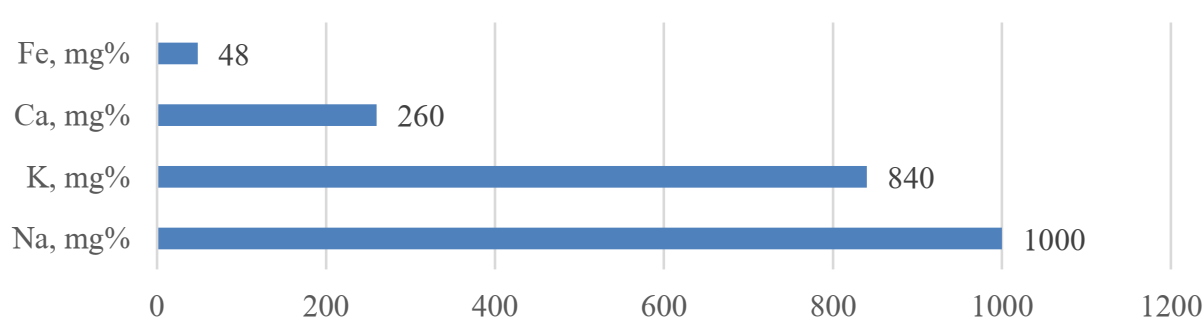

Fig. 2. Mineral composition of buckwheat hull fine powder.

The known ways of melanin obtaining are synthetic method, extraction from chaga mushrooms, mulberry fruits, grape pomace, fruit and vegetable processing industry byproducts (apple, pomegranate, persimmon, black carrot, red beet pulp) [13, 14]. It is worth that obtaining melanin from buckwheat hulls is most profitable since they are renewable waste material with minimal practical use. It was found that preliminary mechanochemical treatment of buckwheat hulls increases the melanin yield by $14.36 \%$.

Technology of melanin obtaining is shown in Fig. 3.

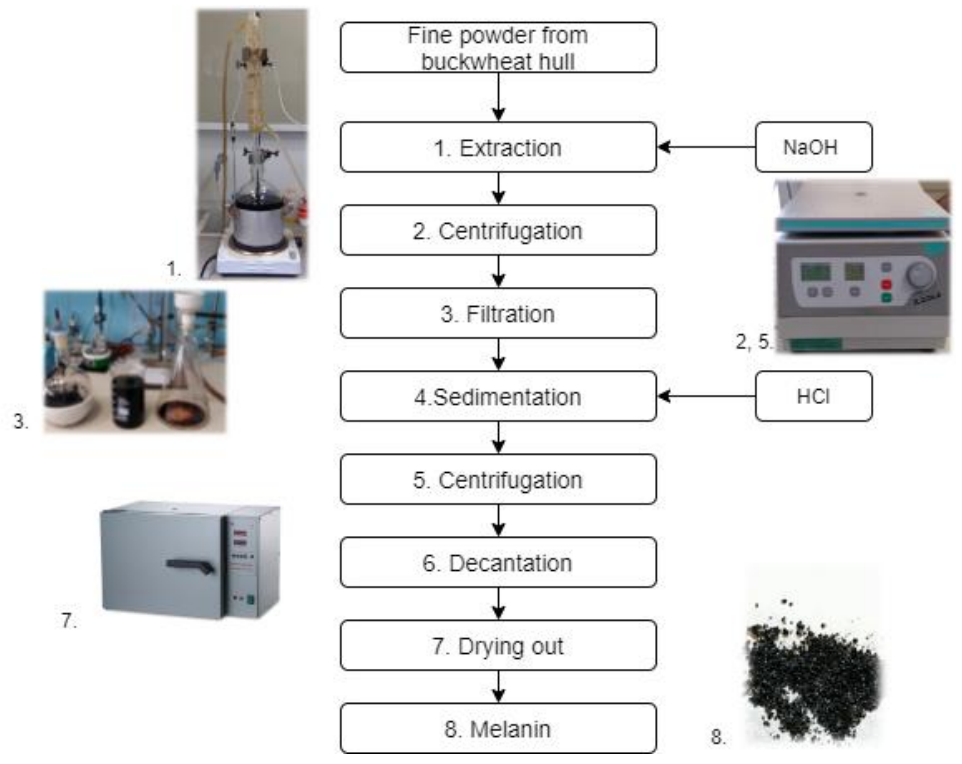

Fig. 3. Technology of melanin obtaining.

For melanin isolation, buckwheat hull sample of about $10 \mathrm{~g}$ was extracted with a 0.1 $\mathrm{mol} / \mathrm{l} \mathrm{NaOH}$ aqueous solution with a hydromodule of $1 / 10$ at $60{ }^{\circ} \mathrm{C}$ during $60 \mathrm{~min}$., then the extract was filtered. After that, $\mathrm{pH}$ of the solution was brought to weak acid by $0.2 \mathrm{~mol} / \mathrm{l}$ $\mathrm{HCl}$ aqueous solution. The formed melanin was filtered off, washed with water, and dried at $105{ }^{\circ} \mathrm{C}$. Alkaline hull left over from melanin obtaining can be used for liming agricultural soils instead of lime itself [12].

Melanin yield was about $5 \%$, and its solubility was less than $0.087 \mathrm{~g}$ per 1 liter at $23{ }^{\circ} \mathrm{C}$.

Obtained buckwheat hull fine powder and melanin can be used as functional food ingredients in formulations of enriched or functional food products, such as desserts (berry cream, chocolate cream, berry mousse), cottage cheese semi-finished products and dishes, pate and flour confectionery. Introduction of fine powder and melanin increases antioxidant activity and dietary fiber content of enriched products. 
In the paper, chocolate cream with buckwheat hull fine powder and melanin was studied as an experimental sample of enriched food product. In accordance with Russian Methodical Recommendations 2.3.1.1915-04, melanin and buckwheat hull powder amounts were calculated. The calculation was carried out according to the norms of consumption of quercetin considering its toxicity.

\section{Results and discussion}

As a result of research, sensory quality characteristics of obtained buckwheat hull and melanin powders (Table 1) were determined.

Table 1. Sensory characteristics of buckwheat processing by-products.

\begin{tabular}{|c|c|c|}
\hline $\begin{array}{c}\text { Sensory } \\
\text { characteristic }\end{array}$ & $\begin{array}{c}\text { Buckwheat hull } \\
\text { fine powder }\end{array}$ & Melanin \\
\hline Taste and smell & $\begin{array}{c}\text { Pronounced for } \\
\text { buckwheat }\end{array}$ & Lack \\
\hline Appearance & Fine powder & $\begin{array}{c}\text { Fine powder or } \\
\text { granules }\end{array}$ \\
\hline Color & $\begin{array}{c}\text { From brown to dark } \\
\text { brown }\end{array}$ & $\begin{array}{c}\text { From dark brown } \\
\text { to black }\end{array}$ \\
\hline
\end{tabular}

Determination of antioxidant activity (AOA) of buckwheat hull powder and melanin was held on "Color Yauza-01-AA" device according to the procedure for measuring watersoluble antioxidants № 31-07 from May 4, 2007 (№ 20706-05). The results are presented in Table 2.

Table 2. Results of samples antioxidant activity determination.

\begin{tabular}{|l|c|}
\hline \multicolumn{1}{|c|}{ Sample } & \multicolumn{1}{|c|}{$\begin{array}{c}\text { AOA, mg of quercetin } \\
\text { by } \mathbf{1} \text { g of sample }\end{array}$} \\
\hline Buckwheat hull fine powder & 2.0 \\
\hline Melanin & 119.0 \\
\hline
\end{tabular}

According to obtained data, it was decided to develop formulations of functional desserts (chocolate creams) with increased AOA. A functional product is a product that contains at least $15 \%$ of a functional ingredient of its daily requirement per serving. For one cream portion $(100 \mathrm{~g})$ buckwheat hull fine powder content was $1.5 \mathrm{~g}$, and melanin content was $0.037 \mathrm{~g}$. These amounts provide the functionality of ready desserts, according to the daily antioxidant norm of approximately $30 \mathrm{mg}$.

In the dessert samples, sensory and physico-chemical indicators were evaluated. Tasting analysis of developed creams was carried out with the use of descriptive and profile method, which clearly demonstrates sensory characteristics of obtained samples (Fig. 4 and Fig. 5). Introducing melanin into cream formulation had absolutely no effect of sensory characteristics of ready desserts due to its lack of buckwheat taste and smell. Buckwheat hull powder gave a slight buckwheat flavor and smell to the dessert sample. By the way, that did not affect on its sensory profile picture.

The following dessert samples were developed:

- sample № 1 - chocolate cream (control);

- sample № 2 - chocolate cream with melanin;

- sample № 2 - chocolate cream with buckwheat hull powder. 


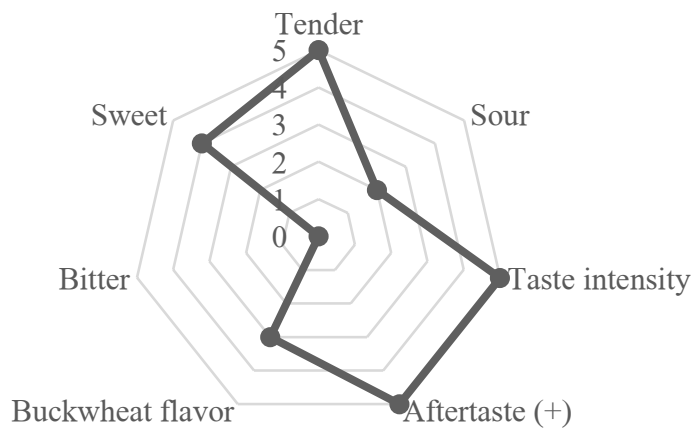

Fig. 4. Taste profilogram of dessert with melanin.

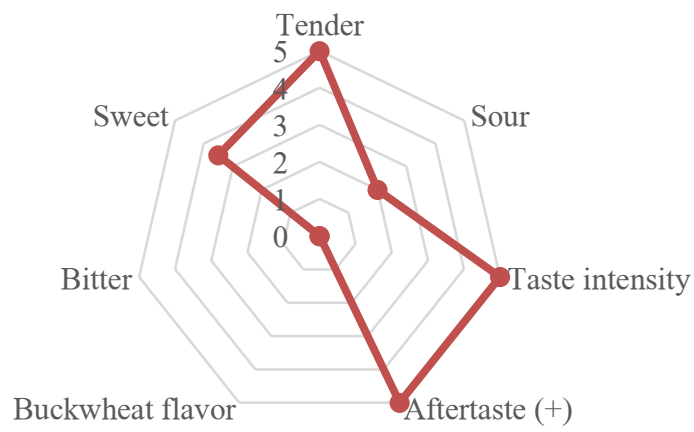

Fig. 5. Taste profilogram of dessert with buckwheat hull powder.

Obtained dessert samples were evaluated on physico-chemical quality indicators. The results are shown in Table 3.

Table 3. Physico-chemical indicators of dessert samples.

\begin{tabular}{|l|c|c|c|}
\hline \multicolumn{1}{|c|}{ Indicators } & Sample № 1 & Sample № 2 & Sample № 3 \\
\hline Humidity, \% & $31.6 \pm 0,1$ & $32 \pm 0.1$ & $26 \pm 0.1$ \\
\hline Acidity, ${ }^{\circ} \mathrm{T}$ & $40 \pm 0,2$ & $43 \pm 0.2$ & $41 \pm 0.2$ \\
\hline Sugar content, \% & $22 \pm 0,2$ & $21.5 \pm 0.2$ & $24 \pm 0.2$ \\
\hline Cellulose content, mg\% & $1.8 \pm 0.015$ & $1.9 \pm 0.015$ & $2.305 \pm 0.015$ \\
\hline Ash content, \% & $0.2 \pm 0.015$ & $0.23 \pm 0.015$ & $0.27 \pm 0.015$ \\
\hline $\begin{array}{l}\text { AOA, mg of quercetin } \\
\text { by 1 g of sample }\end{array}$ & $0.09 \pm 0.01$ & $0.126 \pm 0.01$ & $0.121 \pm 0.01$ \\
\hline
\end{tabular}

\section{Conclusions}

Melanin obtained from buckwheat hulls is of a greatest interest, since its production, as opposed to production of melanins of animal origin or chemically synthesized from expensive reagents, is not limited by raw materials. Therefore, buckwheat hulls processing allows rational and effective use of natural resources, reduces the amount of grain processing industry wastes, and thereby meets some of the targets of the Sustainable Development Goals. Melanin and buckwheat hull powder also can be realized as food 
additives reach with dietary fibers and antioxidants [15]. In contrast to fine buckwheat hull powder, melanin does not affect the sensory characteristics of food products. Therefore, it can be used for enriching such food products as creams, mousses, desserts and flour confectionery products. The introduction of fine buckwheat powder into food products in optimal ratio does not affect their sensory characteristics. It is determined that the use of buckwheat hull powder in desserts formulations increases both their AOA and dietary fiber content. The number of antioxidants in developed creams fulfills is more than $15 \%$ of their daily norm. In the future, it is planned to study the possibility of using obtained powders in the development of drinks and flour confectionery products.

\section{References}

1. S. S. Stavitskaya, T. I. Mironyuk, N. T. Kartel', V. V. Strelko, Russ. J. Appl. Chem., 4, 592 (2001)

2. O. Chugunova, M. Shkolnikova, E. Kadritskaya, E3S Web Conf., 208, 01009 (2020)

3. V. N. Kovalev, I. A. Konkina, Pharmaceutical Journal, 3 (1991)

4. H. Brockman, E. Weber, E. Sander, Naturwissenshauften, 2 (1950)

5. S. H. Wender, R. A. Gortner, O. L. Luman, Jour. Amer. Chem. Soc., 65, 1733 (1943)

6. A. Makowska, M. Majcher, S. Mildner-Szkudlarz, A. Jedrusek-Golinska, K. Przygon'ski, J. Food Sci. Technol., 10, 3092 (2017)

7. X. Li, D. Li. J. Shmidt, V. Grishchenko, T. Kalenik, J. Med. Plant Res., 4, 572 (2011)

8. A. I. Devyatkin, Rational use of forages (1990)

9. V. A. Kurkin, Pharmacognosy: textbook for pharmaceutical students (2004)

10. N. V. Gracheva, V. F. Zheltobryukhov, Bulletin of the Technological University, 15, 154 (2016)

11. A. Kunwar, B. Adhihary, S. Jayakumar, A. Barik, S. Chattopadhyay, S. Raghukumar, K. I. Priyadarsini, Toxicol. Appl. Pharmacol., 2, 202 (2012)

12. A. A. Ivanova, I. E. Andrianova, V. N. Maltsev, A. N. Abrosimova, T. M. Bulynina, S. V. Vorozhtsova, Y. S. Severyukhin, Medicine of Extreme Situations, 4, 66 (2014)

13. B. N. Ogarkov, G. R. Ogarkova, L. V. Samusenok, Medicinal mushrooms from the ecosystems of South Baikal (2012)

14. E. B. Arikan, O. Canli, Y. Caro, L. Dufossé, N. Dizge, J. Fungi (Basel), 4, 240 (2020)

15. I. V. Matseychik, S. M. Korpacheva, I. O. Lomovsky, K. R. Serasutdinova, IOP. Conf. Ser. Earth Environ. Sci., 640, 022038 (2021) 